\title{
Book review: Turquoise, Water, Sky: Meaning and Beauty in Southwest Native Arts
}

\author{
David E. Witt \\ SUNY Buffalo. 380 Fillmore Academic Center, Ellicott Complex, University at Buffalo, Buffalo, New York, \\ 14261-0026. United States of America. Email: dwitt@buffalo.edu
}

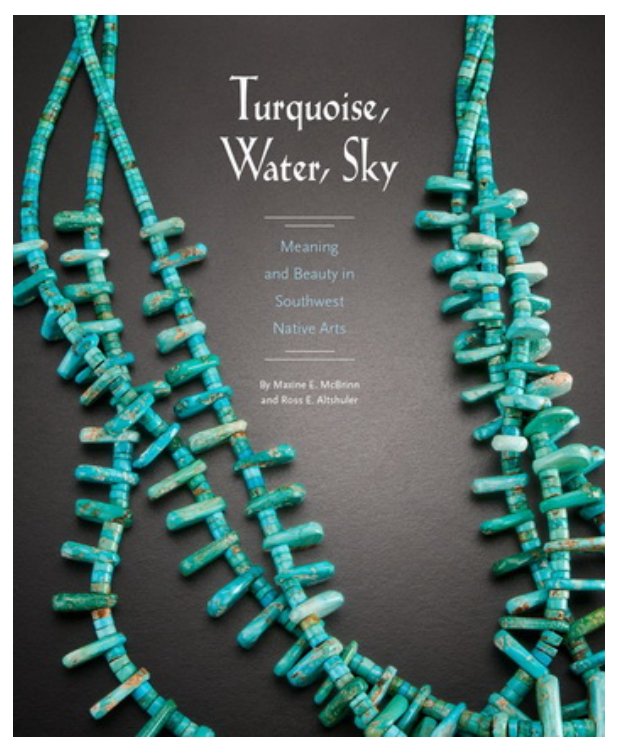

Turquoise, Water, Sky: Meaning and Beauty in Southwest Native Arts

by Maxine E. McBrinn and Ross E. Altshuler

Museum of New Mexico Press, 2015, pp. 172. ISBN 978-0-89013-604-1

http://www.unmpress.com/books.php?ID=20000000006839

Turquoise, Water, Sky: Meaning and Beauty in Southwest Native Arts presents an accessible discussion of the importance and utilization of turquoise by Southwestern cultures throughout the past 1500 years, albeit heavily focused on the modern era. Primarily meant for a lay audience, this short volume is divided into six chapters and interspersed by approximately 160 images and illustrations. While beautiful, these images greatly limit the amount of text in the book. Turquoise, Water, Sky begins with a discussion of the prehistoric use of the material and its meaning in both past and contemporary contexts. However, the majority of the volume presents an evolution of contemporary form of both Puebloan and Navajo stonework. This portion will likely be the most appealing aspect of the book for the

Published by the School of History, Classics and Archaeology, University of Edinburgh ISSN: 2055-0472. URL: http://journals.ed.ac.uk/lithicstudies/

This work is licensed under a Creative Commons Attribution 2.5 UK: Scotland License. 
intended general audience, but it has limited utility for archaeologists and others interested in lithic studies.

The first chapter of the book, "Turquoise, Water, Sky," briefly presents the use of the material throughout the ancient world, then quickly dives into the geological and chemical nature of the mineral. The authors describe how the mineral forms in arid regions as water slowly percolates through host rock and deposits dissolved metals. Various proportions of these metals result in the variety of colours for which turquoise is known. This information is useful for a lay reader, though perhaps too introductory for specialists. The second chapter, "Turquoise and Blue-Green in the Distant Past," focuses on prehistoric use of the mineral, and it is this chapter that may prove most useful for archaeologists. The authors equate the blue, blue-green, or green mineral with life-giving water not only because of its colour, but also how it was utilized in combination with shell. Furthermore, they argue the form of many effigy vessels (that reference creatures associated with water, such as fish or waterfowl) illustrate the importance of water in an arid environment and repeat the theory that hachured paint on ceramics may illustrate blue-green when that colour is not available using paint that would survive a firing process. This discussion is reiterated in the following chapter, "Water and Sky: The Meaning of Turquoise." However, both these arguments are brief and lack references to original or supporting materials.

The next three chapters present the utilization of turquoise by Southwestern cultures. "Tradition and Innovation: Pueblo Use of Turquoise" approaches this broad topic by community (e.g., Santo Domingo, Zuni, Hopi, Acoma) but does draw out reoccurring and common themes of turquoise representing water, sky, or growing plants. This contrasts to the fifth chapter, "Protection and Health: Navajo Use of Turquoise," which discusses how the mineral is linked to personal protection, and often given to new born Navajo infants. The volume concludes with "Into the Future: Contemporary Forms," a discussion of the evolution of turquoise jewellery.

This book is a very good example of how archaeologists can reach out to the general public. However, with that being said, its utility for researchers is extremely limited. Unfortunately, it is very light on references (only two!), and even the "Further Reading" section in the bibliography is light on scientific sources. This is particularly disappointing, as much research has been done on the mineral and its utilization and trade by pre-Columbian societies in the American Southwest and it would have been nice to have seen that research documented in an expanded bibliography. Yet the book does contain a hidden gem: The appendix describes 31 different turquoise sources, many with brief discussions of the colour and matrix of the material, as well as the history of the mine. This may help researchers understand the differences between various turquoise sources discussed within the academic literature presented elsewhere.

While a beautiful book, the reviewer finds it to be of limited usefulness. It would be most suited for those who appreciate and collect southwestern jewellery as artwork, and perhaps not relied upon as an academic text in its own right. 